\title{
Body weight perception, knowledge, practices and associated factors regarding weight reduction: A cross sectional study of treatment seeking obese young adults in Sri Lanka
}

\author{
Gayani Priyangika Gamage ${ }^{1}$, Priyadarshika Hettiarachchi², Ranil Jayawardena ${ }^{3}$, \\ Sudharshani Wasalathanthri ${ }^{4}$ \\ ${ }^{1}$ Lecturer, Department of Nursing and Midwifery, Faculty of Allied Health Sciences, General Sir John Kotelawala \\ Defence University, Boralesgamuwa, Sri Lanka, ${ }^{2}$ Professor, Department of Physiology, Faculty of Medical Sciences, \\ University of Sri Jayewardenepura, Nugegoda, Sri Lanka, ${ }^{3,4}$ Professor, Department of Physiology, Faculty of Medicine, \\ University of Colombo, Colombo, Sri Lanka
}

Background: Obesity and its' comorbidities in young adults are emerging health concerns. Obesity is a well-known risk factor for developing cardiovascular diseases, type -2 diabetes, carcinomas, gallbladder disease, sleep apnea, osteoarthritis, and gynecological complications. Young adulthood is considered the best time period to introduce weight control interventions as the established lifestyle behaviors may persist throughout life. Aims and Objectives: The present study assessed self-perception of body weight, knowledge and practices on obesity and weight reduction and their associated factors in a sample of treatment seeking obese young adults. Materials and Methods: Two-hundred and sixty-one obese (BMI $\geq 25 \mathrm{~kg} \mathrm{~m}^{-2}$ ) young (18-35 years) adults attending an out-patient nutrition clinic of a teaching hospital in Sri Lanka were studied. An interviewer administered questionnaire was used to collect demographic data and information on body weight perception and, knowledge and practices on obesity and weight reduction. Weight, height and waist circumference were measured. Results: The mean $\left( \pm\right.$ SD) BMI of the participants was $29.0( \pm 3.6) \mathrm{kg} \mathrm{m}^{2}$. Only $16.1 \%$ precisely perceived themselves as 'obese' and increased BMI was only significant predictor of accurate body weight perception (OR $=1.23 ; 95 \% \mathrm{Cl}=1.07-1.47 ; p=0.003)$. Only $49.0 \%$ reported obesity as a disease and $46.0 \%$ and $27.2 \%$ that it predisposes to stroke and carcinoma respectively. Although $86.2 \%$ have attempted weight reduction, only $33.8 \%$ sought professional advice. Diet control was the most common weight reduction strategy $(73.1 \%)$ and among them $33.3 \%$ combined with exercises. One fourth $(n=56)$ relied on green tea for weight reduction and meal skipping was reported in $52.9 \%$. Conclusion: Significant body weight misperception was reported in lower BMI categories. The overall knowledge regarding obesity and weight reduction was satisfactory though not optimum. Diet control with or without physical exercises was the most popular method of weight reduction.

Keywords: Body weight perception; Knowledge; Weight reduction practices; Obesity; Young adults

\section{Access this article online}

Website:

http://nepjol.info/index.php/AJMS DOI: 10.3126/ajms.v12i9.37670

E-ISSN: 2091-0576

P-ISSN: 2467-9100

Copyright (c) 2021 Asian Journal of Medical Sciences

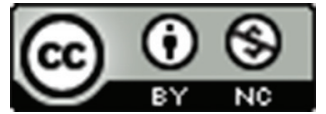

This work is licensed under a Creative Commons Attribution-NonCommercial 4.0 International License. 


\section{INTRODUCTION}

Obesity is defined as deposition of excess body fat that carries a risk to health ${ }^{1}$ which is recently defined as a disease. ${ }^{2}$ Obesity is a well-known risk factor for developing cardiovascular diseases, type -2 diabetes, carcinomas, gallbladder disease, sleep apnea, osteoarthritis, and gynecological complications. ${ }^{2}$ There is an increasing evidence that South Asians are more vulnerable for obesity related comorbidities with lower BMI and waist circumference cutoffs as they have a higher percentage of body fat compared to Caucasians. ${ }^{3}$ Though obesity carries a risk for individuals of all ages, the young adults belong to one of the high risk categories that have been mostly overlooked. ${ }^{4}$

Young adulthood is allied with a variety of significant life events such as leaving residence for occupation or higher education, marriage, pregnancy and child bearing that are known to be associated with weight gain. ${ }^{5}$ In addition, unhealthy behaviors which include the use of fast food, sugarsweetened beverages and alcohol, and sedentary lifestyle are contributory factors for weight gain in this age group. ${ }^{5}$ Since individuals establish their lifestyle behaviors during young adulthood, this period of life is considered perfect for introducing obesity prevention interventions which may persist throughout life. ${ }^{4}$ Exploring perceptions towards obesity and weight reduction are reported to be helpful in developing strategies targeting this vulnerable age group. ${ }^{4}$

Accurate body weight perception is a motivating factor for weight reduction practices. ${ }^{6}$ Furthermore, obese individuals who misperceive their body size show less active participation in weight reduction programs as they are less aware of the risks associated with obesity. ${ }^{7}$ In Sri Lanka, body weight misperception has been reported in healthy obese $^{8}$ as well as in patients suffering from cardiovascular diseases. ${ }^{9}$ Moreover, more than $2 / 3$ of overweight and $1 / 3$ of obese Sri Lankan adults believe that they are in the right weight or in the underweight category. ${ }^{10}$

As previous reports are confined more to the general population, our focus was to assess body weight perception, knowledge and practices on obesity and weight reduction and their associated factors of a selected group of treatment seeking obese young adults. The outcomes of this study would offer important insights in developing weight management protocols targeted specifically for this group.

\section{MATERIALS AND METHODS}

\section{Study population and sampling}

A convenient sample of 261 subjects aged between 1835 years with $\mathrm{BMI} \geq 25 \mathrm{kgm}^{-2}$, attending to a nutrition clinic of a teaching hospital in Colombo District, Sri Lanka during June 2018 to May 2019 was studied. Eligible participants who met the selection criteria were included in the study until the expected sample size was achieved. Written informed consent was obtained at recruitment. The study was approved by the Ethics Review Committee, Faculty of Medicine, University of Colombo, Sri Lanka.

\section{Baseline information}

Socio-demographic details obtained were age, gender, ethnicity, level of education, civil status, employment status and monthly household income. Height, weight and waist circumference were measured and BMI was calculated. Subjects were classified into three groups according to their measured BMI values: Obesity Class I (25-30 $\left.\mathrm{kg} \mathrm{m}^{-2}\right)$, Class II (30-35 $\mathrm{kg} \mathrm{m}^{-2}$ ) and Class III $\left(\geq 35 \mathrm{~kg} \mathrm{~m}^{-2}\right),{ }^{11}$ Abdominal obesity was defined as per the waist circumference $>90 \mathrm{~cm}$ for males and $>80 \mathrm{~cm}$ for females. ${ }^{11}$ The ideal body weight (IBW) was calculated by using body weight as a function of height and the upper limit of the normal BMI value for Asians (IBW $(\mathrm{kg})=$ (22.9 $\mathrm{kg} \mathrm{m}^{-2} \mathrm{x}$ height $\left.\left.^{2}\right)\right) .{ }^{11}$

\section{Data on body weight perception, obesity and weight} reduction

Data were collected by an interviewer-administered questionnaire. The body weight perception was assessed by a single question; 'How do you describe your weight?' with four choices, underweight, about the right weight, overweight, and obese.' The questions on knowledge were adapted from a questionnaire validated elsewhere ${ }^{12}$ and subsequently face validated by the investigators. The participants were asked to respond on a 3 - point Likert scale to 23 statements on knowledge regarding obesity and weight reduction with scoring as True $=2$, Don't Know $=1$ and False $=0$ for knowledge. The maximum score for knowledge was 46. The meal skipping behavior was assessed using a Yes/No type question and details of weight reduction practices were obtained by a multiplechoice question allowing individuals to select all methods they have used for weight reduction.

\section{Statistical analysis}

The data analysis was performed using SPSS version 23 (SPSS Inc., Chicago, IL, USA). The Pearson's chi-square test was used to assess associations between categorical variables. The percentages of body weight perception categories were reported according to categories of demographic and anthropometric variables. Overall knowledge was presented as descriptive statistics and overall knowledge score was categorized into two groups below and above the median and compared between different groups of sociodemographic and anthropometric variables. A multiple logistic regression analysis was carried out with body weight 
perception as the dependent variable and age, gender, BMI, and waist circumference as independent variables. All independent variables were assessed separately with the dependent variable and the independent variables with $p>0.25$ were simultaneously included in the regression model regardless of their statistical significance. The Hosmer- Lemeshow goodness-of-fit test was used to assess model fitness and non-significant $p$ value was considered as a 'good' model. In all analyses, a $p$ value $<0.05$ was considered as statistically significant.

\section{RESULTS}

Two hundred and sixty-one adults participated in the study. Table 1 shows the summary statistics for sociodemographic and anthropometric characteristics of the study population. Majority of participants were females $(n=151,57.9 \%)$. Overall, there was a preponderance of Sinhalese. In the study population, majority belonged to obesity class I. The mean ( \pm SD) BMI of the sample was $29.0( \pm 3.6) \mathrm{kgm}^{-2}$.

Table 2 shows the body weight perception of participants grouped according to the gender. Although the entire sample was obese, only $16.1 \%$ perceived themselves

\begin{tabular}{|c|c|c|c|c|}
\hline \multicolumn{2}{|l|}{ Variables \%(n) } & $\begin{array}{l}\text { Overall } \\
(261)\end{array}$ & $\begin{array}{l}\text { Males } \\
(110)\end{array}$ & $\begin{array}{l}\text { Females } \\
\text { (151) }\end{array}$ \\
\hline \multicolumn{2}{|c|}{ Age (Years) (Mean \pm S.D.) } & $27.9 \pm 5.6$ & $26.3 \pm 5.4$ & $29.0 \pm 5.4$ \\
\hline \multicolumn{2}{|c|}{ BMI $\left(\mathrm{kgm}^{-2}\right)($ Mean \pm S.D.) } & $29.0 \pm 3.9$ & $28.6 \pm 2.6$ & $29.2 \pm 4.2$ \\
\hline \multirow[t]{4}{*}{ Ethnicity } & Sinhalese & $94.6(247)$ & $95.5(105)$ & $94.0(142)$ \\
\hline & Muslim & $1.9(5)$ & $0.9(1)$ & $2.6(4)$ \\
\hline & Tamil & $2.3(6)$ & $2.7(3)$ & $2.0(3)$ \\
\hline & Other & $1.1(3)$ & $0.9(1)$ & $1.3(2)$ \\
\hline \multirow{5}{*}{$\begin{array}{l}\text { Highest level } \\
\text { of education }\end{array}$} & No schooling & $2.3(6)$ & $2.7(3)$ & $2.0(3)$ \\
\hline & Up to year 5 & $4.6(12)$ & $8.2(9)$ & $2.0(3)$ \\
\hline & Up to year 11 & $44.1(115)$ & $40.0(44)$ & $47.0(71)$ \\
\hline & Up to year 13 & $39.1(102)$ & $40.0(44)$ & $38.4(58)$ \\
\hline & $\begin{array}{l}\text { Diploma and } \\
\text { degree }\end{array}$ & $10.0(26)$ & $9.1(10)$ & $10.6(16)$ \\
\hline \multirow[t]{3}{*}{ Civil status } & Unmarried & $45.6(119)$ & $61.8(68)$ & $33.8(51)$ \\
\hline & Married & $52.5(137)$ & $38.2(42)$ & $62.9(95)$ \\
\hline & Divorced/Widowed & $1.9(5)$ & $0.0(0)$ & $3.3(5)$ \\
\hline \multicolumn{5}{|l|}{ Status } \\
\hline Monthly family & Low $(<30000)$ & $22.2(58)$ & $16.4(18)$ & $26.5(40)$ \\
\hline \multirow[t]{2}{*}{ income (SLR) } & $\begin{array}{l}\text { Middle (30000- } \\
60000)\end{array}$ & $44.1(115)$ & $40.0(44)$ & $47.0(71)$ \\
\hline & High $(>60000)$ & $33.7(88)$ & $43.6(48)$ & $26.5(40)$ \\
\hline \multirow[t]{3}{*}{ Obesity class } & Class I (25 & $66.3(173)$ & $66.4(73)$ & $66.2(100)$ \\
\hline & $\begin{array}{l}\left.\geq \mathrm{BMI}<30 \mathrm{kgm}^{-2}\right) \\
\text { Class II }(30 \\
\left.\geq \mathrm{BMI}<35 \mathrm{kgm}^{-2}\right)\end{array}$ & $28.0(73)$ & $32.7(36)$ & $24.5(37)$ \\
\hline & $\begin{array}{l}\text { Class III (BMI } \geq 35 \\
\left.\mathrm{kgm}^{-2}\right)\end{array}$ & $5.7(15)$ & $0.9(1)$ & $9.3(14)$ \\
\hline \multicolumn{2}{|c|}{ Central Obesity* } & $92.3(241)$ & $81.8(90)$ & $100.0(151)$ \\
\hline
\end{tabular}

accurately as being 'obese'. However, only 11.1\% $(n=29)$ of them misperceived themselves as being 'about right weight' or 'no idea'. The body weight misperception was likely to be higher among males compared to females $(62.9 \%$ vs $37.1 \% ; p=0.021)$. Table 3 shows the body weight perception of participants grouped according to the obesity class they belong to. The Hosmer- Lemeshow goodnessof-fit test was not significant for the model of body weight perception. According to results of the multiple regression analysis, higher BMI was the only significant predictor of accurate body weight perception $(\mathrm{OR}=1.23$; 95\% CI $=1.07$ $1.47, p=0.003)$. Moreover, only 31.8\% $(n=83)$ expressed their preferred body weight closer to the calculated IBW $( \pm 2 \mathrm{~kg})$. The rest of the participants preferred either higher or lower values than ideal body weight.

Median knowledge score of the cohort regarding obesity and weight reduction was 38.0 (scale; 0-46) with $60.2 \%$ $(n=157)$ scoring above the median value. Although only $49 \%(n=128)$ of obese were aware that obesity is considered as a disease, more than $90 \%$ reported that obesity predisposes to coronary artery disease, hypertension, diabetes mellitus and hypercholesterolemia. However, the relationship between obesity and osteoporosis, stroke and carcinomas were recognized only by $65.9 \%, 46 \%$ and $27.2 \%$ respectively. Majority of the participants were aware that obesity can develop at any age (96.9\%), gives a low appearance self-esteem to an individual (89.7\%), may lead to early disability $(96.6 \%)$, and psychological (96.6\%) and physical $(91.2 \%)$ problems. Further, females were likely to have an increased overall knowledge (52.2\% vs $47.8 \% ; p=0.024)$ and the specific knowledge that obesity is considered a disease $(68 \%$ vs $32 \% ; p=0.001)$.

On Exploration of weight reduction practices, although $86.2 \%(n=225)$ of the participants have attempted weight

$\begin{aligned} & \text { Table 2: Body weight perception of participants } \\
& \text { by gender }\end{aligned}$
\begin{tabular}{lcccc}
\hline Gender & \multicolumn{4}{c}{ Body Weight Perception Categories } \\
\cline { 2 - 5 } & $\begin{array}{c}\text { About right } \\
\text { weight (\%) }\end{array}$ & $\begin{array}{c}\text { Overweight } \\
(\%)\end{array}$ & $\begin{array}{c}\text { Obese } \\
(\%)\end{array}$ & $\begin{array}{c}\text { No idea } \\
(\%)\end{array}$ \\
\hline Male (110) & $11(10.0)$ & $80(72.7)$ & $12(10.9)$ & $7(6.4)$ \\
Female (151) & $5(3.3)$ & $110(72.8)$ & $30(19.9)$ & $6(4.0)$ \\
Overall (261) & $16(6.1)$ & $190(72.8)$ & $42(16.1)$ & $13(5.0)$ \\
\hline
\end{tabular}

Table 3 : Body weight perception of participants by obesity class

\begin{tabular}{lcccc}
\hline Obesity Class & \multicolumn{4}{c}{ Body Weight Perception Categories } \\
\cline { 2 - 5 } & $\begin{array}{c}\text { About right } \\
\text { weight (\%) }\end{array}$ & $\begin{array}{c}\text { Overweight } \\
\mathbf{( \% )}\end{array}$ & $\begin{array}{c}\text { Obese } \\
\mathbf{( \% )}\end{array}$ & $\begin{array}{c}\text { No Idea } \\
\text { (\%) }\end{array}$ \\
\hline Class I & $11(6.4)$ & $135(78.0)$ & $19(11.0)$ & $8(4.6)$ \\
Class II & $5(6.8)$ & $49(67.1)$ & $15(20.5)$ & $4(5.5)$ \\
Class III & $0(0.0)$ & $6(40.0)$ & $8(53.3)$ & $1(6.7)$ \\
\hline
\end{tabular}


reduction at least once, only $33.8 \%(n=76)$ of them have sought professional advice for it. All participants who had accurate body weight perception had attempted weight reduction at least once and $54.8 \%(n=23)$ of them had sought professional advice for it. Accurate body weight perception was likely to be higher in those with previous attempts of weight reduction $(100.0 \%$ vs $0.0 \% ; p=0.005)$ and tendency to seek professional advice $(54.8 \%$ vs $45.2 \% ; p<0.001)$. Of the total sample, $52.9 \%(n=138)$ of participants have skipped at least one meal per day to achieve weight reduction and of them, breakfast alone was skipped by $37.7 \%(n=52)$, lunch alone by $19.6 \%(n=27)$, dinner alone by $29.0 \%(n=40)$ and two meals on varying combinations by $13.8 \%(n=19)$.

When self-reported weight reduction methods adopted by participants were explored, diet control alone was used by $39.8 \%(n=104)$ while physical exercises alone by $6.9 \%(n=18)$. A combination of both methods was adopted by $33.3 \%(n=87)$. Further, nearly one-fourth of the participants $(n=56)$ relied on green tea as a weight reduction strategy whereas $6.7 \%(n=16)$ of the participants adopted to traditional methods such as garlic and bees honey paste, kanji made out of curry leaves and 'Aralu' (Chebulic Myrobalan) tablets or powder etc.

\section{DISCUSSION}

The areas of body weight perception, obesity and weight reduction are extensively researched among various categories of young adult populations globally. ${ }^{6,13}$ Exploring the viewpoints of obese young adults seeking professional assistance to ameliorate the problems associated with obesity are considered vital in planning appropriate interventions for weight reduction. There was a female predominance in the study cohort which may either be due to higher prevalence of overweight and obesity reported among females ${ }^{3}$ or more females seeking out solutions for obesity probably because they are more concerned about their body weight status and appearance. ${ }^{14}$

Self-awareness of body weight is an important factor to maintain an optimum weight. ${ }^{8,13}$ In the current study, only $16.1 \%$ perceived their body weight precisely as 'obese' while the vast majority perceived them as 'overweight' and only a minority misperceived themselves as 'about right weight' or 'no idea'. A comparatively higher percentage of body weight misperception has been reported previously $(46.9 \%)$ in Sri Lankan obese cardiac patients. ${ }^{9}$ Moreover, it was found that higher the BMI, greater the accuracy of body weight perception which is contrary to that of Barichella et al., who reported increased tendency of weight misperception in individuals with higher BMI values. ${ }^{15}$ The possible explanation for these differences could be due to the availability of recent body weight measurements for treatment seeking individuals of the present study to have a better understanding of their weight status.

The overall knowledge on obesity and weight reduction appeared satisfactory among the participants in the present study presumably because the questionnaire mainly tested basic knowledge. The females reported to have more knowledge which may be attributed to their willingness to seek advice from health personnel and the tendency to participate in educational sessions. ${ }^{16}$ Similarly, studies conducted elsewhere on overweight and obese adults have reported adequate levels of knowledge, although it was not significantly associated with the gender. ${ }^{17}$ However, during in-depth exploration of specific knowledge, it was evident that only about half of the obese adults of the current study acknowledged that obesity is a disease. In a Nigerian study, comparatively higher percentage $(75.8 \%)$ reported obesity as a disease ${ }^{17}$ probably because of more intense educational inputs due to the higher prevalence of obesity in African Americans. ${ }^{18}$ In accordance with previous findings, ${ }^{19}$ vast majority of treatment seeking adults in the present study were knowledgeable of the common comorbidities associated with obesity. Yet surprisingly, more than half of the cohort did not know that obesity predisposes to stroke and carcinoma which are two diseases grouped among the five leading causes of mortality. ${ }^{20}$ Nevertheless, an European study reported a low level of knowledge regarding obesity related health risks in sample of obese adults despite attending to a weight management clinic for 18 months and obesity related comorbidities present in a vast majority of them. ${ }^{21}$

In the present study, most of the participants not seeking professional advice despite them attempting weight reduction is a point of concern. Unavailability of sufficient weight reduction facilities and difficulties in accessing professional help ${ }^{9}$ are some possibilities that need consideration. In addition, there are reports where health-care professionals have failed to advice on weight reduction despite the obese and overweight individuals recognizing the need for it. ${ }^{15}$ The mere fact that our sample constituted of obese adults attending a nutrition clinic is possibly the reason for the higher percentage reporting a history of attempted weight reduction compared to studies conducted elsewhere. ${ }^{6,22}$ Body weight perception is an important factor that influences weight reduction practices among young adults 8 and inaccuracy of weight perceptions in any direction are linked with unhealthy weight control strategies. ${ }^{22}$ Moreover, overestimation of body weight was reported with increased tendency of attempting weight reduction compared to underestimation ${ }^{13}$ confirming the importance of correct weight perception in weight management. 
A combination of diet control and physical exercises are recommended for effective weight management ${ }^{23}$ and about one third of our cohort adopted to the combined approach which was much higher than the values obtained by previous investigators. ${ }^{17,23}$ In contrary to some of the previous studies performed in the African continent, ${ }^{6,17}$ diet control was far more popular than exercises among our participants who opted for either of the two methods. However, this difference can partly be explained by the fact that South Asians have long been reported to have low levels of physical activity. ${ }^{3}$ Meal skipping is another strategy used for weight control especially in young adults ${ }^{23}$ with breakfast being the commonest meal skipped. ${ }^{24} \mathrm{~A}$ similar trend was seen in the obese young adults of the present study with over half of the cohort skipping at least one meal per day with the commonest meal skipped being the breakfast. Though green tea is not proven to produce clinically significant weight reduction in overweight or obese adults, ${ }^{25}$ nearly one fourth of the participants of the present study have relied on green tea for weight reduction. The possible reason for increased usage of green tea might be the popularity of products made from natural sources due to the misperception that "natural" usually means safe. ${ }^{25}$

There are a few limitations evident in this study. Since this study was conducted in a single clinic in a teaching hospital in an urban setting, the study sample may not represent the whole young adult obese population in the country. Further, majority of the participants were Sinhalese. It is reported that the ethnic minorities are less likely to get medical advices for weight reduction although they have significant misperceptions of body weight. ${ }^{10}$ Further research is important with a large representative sample of obese young adults to have a clear understanding of the issues related to this vulnerable group. Using the actual anthropometric measurements to calculate BMI-based weight status is a strength of this study as most studies have used self-reported height and weight to calculate the BMI where there is a tendency for underestimation. ${ }^{21,22}$

\section{CONCLUSION}

Though treatment seeking obese individuals are expected to have an accurate body weight perception, a considerable percentage of participants of the present study did not precisely perceive their body weights. However, with incremental increase in the BMI, the body weight perception was noted to be better. The overall knowledge of the participants regarding obesity and weight reduction was satisfactory but serious gaps were identified when exploring further on specific areas. Although a majority has attempted weight reduction at least once, only a very few have sought professional advice. Diet control with or without physical exercises was the most popular method of weight reduction in these participants. The results of this study bring out the notion that target populations should be given special attention in improving self-awareness of body weight, knowledge of obese on the overall health benefits of weight control to motivate them to actively engage in effective weight reduction practices with better involvement of health care professionals in the field.

\section{ACKNOWLEDGEMENT}

The authors take this opportunity to thank all the participants of the study for their voluntary participation

\section{REFERENCES}

1. World Health Organization. Obesity and overweight [Online]. 2020 [cited 2021 Jun 3]. Available from: https://www.who.int/ news-room/fact-sheets/detail/obesity-and-overweight

2. De Lorenzo A, Gratteri S, Gualtieri P, Cammarano A, Bertucci P and Di Renzo L. Why primary obesity is a disease? J Transl Med. 2019;17(1):169. https://doi.org/10.1186/s12967-019-1919-y

3. Misra A, Jayawardena R and Anoop S. Obesity in South Asia: Phenotype, Morbidities, and Mitigation. Curr Obes Rep. 2019;8(1):43-52.

https://doi.org/10.1007/s13679-019-0328-0

4. Lanoye A, Gorin AA and LaRose JG. Young Adults' Attitudes and Perceptions of Obesity and Weight Management: Implications for Treatment Development. Curr Obes Rep. 2016;5(1):14-22. https://doi.org/10.1007/s13679-016-0188-9

5. Poobalan AS, Aucott LS, Precious E, Crombie IK and Smith WCS. Weight loss interventions in young people (18 to 25 year olds): a systematic review. Obes Rev. 2010;11(8):580-592. https://doi.org/10.1111/j.1467-789X.2009.00673.x

6. Bhurtun DD and Jeewon R. Body Weight Perception and Weight Control Practices among Teenagers. ISRN Nutr. 2013;2013:1-6. https://doi.org/10.5402/2013/395125

7. Tsai SA, Lv N, Xiao L and Ma J. Gender Differences in Weight-Related Attitudes and Behaviors Among Overweight and Obese Adults in the United States. Am J Mens Health. 2016;10(5):389-398.

https://doi.org/10.1177/1557988314567223

8. Karthijekan K, Jayawardena R, Anthony AA and Arulnithy K. Body weight perception and weight management practices among a group of Sri Lankan university students. Ceylon Journal of Medical Science. 2018;55(2):36-41.

https://doi.org/10.4038/cjms.v55i2.4937

9. Jayawardena R, Punchihewa P, Ranathunga I, Lokunarangoda N, Pathirana AK and Santharaj WS. Body weight perception among Sri Lankan cardiac patients. BMC Obes 3. 2016;3(1): 32. https://doi.org/10.1186/s40608-016-0113-5

10. Jayawardena R, Byrne NM, Soares MJ, Katulanda P and Hills AP. Body weight perception and weight loss practices among Sri Lankan adults. Obes Res Clin Pract. 2014;8(2):e192-e200. https://doi.org/10.1016/j.orcp.2013.05.003

11. Somasundaram N, Rajaratnam D, Wijeyarathne P, Katulanda P, 
de Silva KSH, Wickramasinghe $\mathrm{P}$, et al. Management of obesity. Sri Lanka J Diabetes Endocrinol Metab. 2014;1:55-70.

12. Golshiri P, Yarmohammadi P, Sarrafzadegan N, Yazadani M and Pourmoghaddas $M$. Developing and validating questionnaires to assess knowledge, attitude, and performance toward obesity among Iranian adults and adolescents: TABASSOM study. ARYA Atheroscler. 2012;7:S119-S124.

13. Yost J, Krainovich-Miller B, Budin W and Norman R. Assessing weight perception accuracy to promote weight loss among U.S. female adolescents: A secondary analysis. BMC Public Health. 2010;10(1):465

https://doi.org/10.1186/1471-2458-10-465

14. Gaylis JB, Levy SS and Hong MY. Relationships between body weight perception, body mass index, physical activity, and food choices in Southern California male and female adolescents. Int J Adolesc Youth. 2020;25(1):264-275.

https://doi.org/10.1080/02673843.2019.1614465

15. Barichella M, Malavazos AE, Fatati $G$ and Cereda E. Awareness and knowledge about weight status and management: results from the $1 \mathrm{~d}$ sensitization campaign 'Obesity Day' in northern Italy. Public Health Nutr. 2011;14(10):1813-1822. https://doi.org/10.1017/S136898001100005X

16. Laz TH, Rahman M, Pohlmeier AM and Berenson AB. Leve of nutrition knowledge and its association with weight loss behaviors among low-income reproductive-age women. J Community Health. 2015;40(3):542-548.

https://doi.org/10.1007/s10900-014-9969-9

17. Bolarinde S, Henry M and Daniel I. Knowledge, attitude and practice of weight reduction among overweight and obese individuals. International Research Journal of Pharmacy and Medical Sciences (IRJPMS)., 2018;1(4):59-62.

18. Puhl RM and Liu S. A national survey of public views about the classification of obesity as a disease: Public Views About Obesity as a Disease. Obesity. 2015;23(6):1288-1295. https://doi.org/10.1002/oby.21068

19. Winston GJ, Caesar-Phillips E, Peterson JC, Wells MT, Martinez J, Chen X, et al. Knowledge of the health consequences of obesity among overweight/obese Black and Hispanic adults. Patient Educ Couns. 2014;94(1):123-127. https://doi.org/10.1016/j.pec.2013.09.022

20. Ferrucci L, Giallauria F and Guralnik JM. Epidemiology of Aging. Radiol Clin North Am. 2008;46(4):643-652. https://doi.org/10.1016/j.rcl.2008.07.005

21. Swift JA, Glazebrook C, Anness A and Goddard R. Obesityrelated knowledge and beliefs in obese adults attending a specialist weight-management service: Implications for weight loss over 1 year. Patient Educ Couns. 2009;74(1):70-76. https://doi.org/10.1016/j.pec.2008.07.045

22. Park B, Cho HN, Choi E, Seo DH, Kim N-S, Park E, et al. Weight control behaviors according to body weight status and accuracy of weight perceptions among Korean women: a nationwide population-based survey. Sci Rep. 2019;9(1):9127. https://doi.org/10.1038/s41598-019-45596-z

23. Field $A E$, Haines $J$, Rosner $B$ and Willett WC. Weight-control behaviors and subsequent weight change among adolescents and young adult females. Am J Clin Nutr. 2010;91(1):147-153. https://doi.org/10.3945/ajcn.2009.28321

24. Colić Barić I, Šatalić $Z$ and Lukešić Ž. Nutritive value of meals, dietary habits and nutritive status in Croatian university students according to gender. Int J Food Sci Nutr. 2003;54(6):473-484. https://doi.org/10.1080/09637480310001622332

25. Jurgens TM, Whelan AM, Killian L, Doucette S, Kirk S and Foy E. Green tea for weight loss and weight maintenance in overweight or obese adults. Cochrane Metabolic and Endocrine Disorders Group, editor. Cochrane Database Syst Rev [online]. 2012 [cited 2020 Nov 13]. https://doi.org/10.1002/14651858.CD008650. pub2

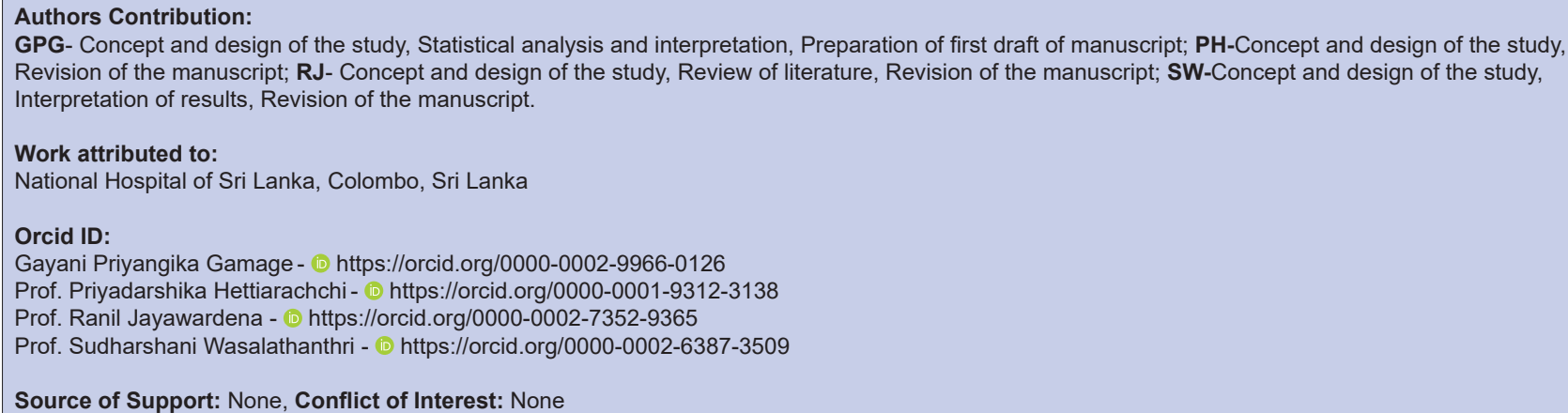

